\title{
Original
}

\section{Effect of Compression Force on Apoptosis in Human Periodontal Ligament Cells}

\author{
Mari Funakoshi' ${ }^{1)}$, Masaru Yamaguchi' ${ }^{2)}$, Masaki Asano ${ }^{2)}$, Syoji Fujita $^{2)}$ and Kazutaka Kasai ${ }^{2)}$ \\ ${ }^{1)}$ Nihon University Graduate School of Dentistry at Matsudo, Orthodontics, Chiba, Japan \\ ${ }^{2}$ Departments of Orthodontics, Nihon University School of Dentistry at Matsudo, Chiba, Japan \\ (Accepted for publication, November 22, 2012)
}

\begin{abstract}
The effect of compression force on periodontal ligament (PDL) plays a critical role in orthodontic tooth movement. However, little is known about this effect on apoptosis and the underlying reactive mechanisms in PDL cells. This study focuses on the application of compression force associated with reactive oxygen species (ROS)-induced apoptosis in PDL cells. Following the application of orthodontic force to maxillary first molars, the molars were investigated using immunohistochemical analysis. The cell cycle and apoptosis were assessed in compression force-treated PDL cells using flow cytometry. Furthermore, we assayed the effect on ROS generation by DCFDA fluorescence. In vivo study revealed an increased number of terminal deoxynucleotidyl transferase-mediated dUTP nick end labeling (TUNEL) and caspase 8-positive cells in the orthodontic force group. In our in vitro study model, the compression force increased the G1 phase and apoptotic cells. A large increase in the intracellular ROS levels in human (h) PDL cells was observed in the compression force group. Taken together, these results provide new information on compression force-induced G1 arrest and apoptosis in hPDL cells.
\end{abstract}

Key words: Apoptosis, ROS, Compression force, Periodontal ligament cell

\section{Introduction}

Orthodontic tooth movement is a multistep biological process characterized by sequential reactions of periodontal tissue against biomechanical forces ${ }^{1}$. The recruitment of osteoclast- and osteoblast-progenitor cells, and the balanced activation of these cells around and within the periodontal ligament (PDL) are essential for alveolar bone remodeling ${ }^{2,3)}$. The application of light orthodontic force causes direct resorption of alveolar bone, while the application of excessive orthodontic force results in excessive compression force, which induces local ischemia, tissue hyalinization, and cell death in the periodontal ligament ${ }^{4}$.

It has been reported in experimental studies that stress produced by orthodontic forces causes a marked increase in the staining intensity of interleukin (IL)- $1 \alpha$ and IL- $1 \beta$ in all cell types of PDL ${ }^{5,6)}$. Tumor necrosis factor (TNF)- $\alpha^{5.6)}$, prostaglandin E2 ${ }^{7)}$, cyclooxygenase $2^{8)}$, and interferon-gamma ${ }^{9)}$ were observed in PDL in experimental tooth movement. Like IL- $1 \beta$, TNF- $\alpha$ plays an important role in mediating immune and inflammatory responses. Moreover, it plays a significant role in the control of proliferation, differentiation and apoptosis ${ }^{10)}$. Regarding the cells

Correspondence to: Dr. Masaru Yamaguchi, Department of Orthodontics, Nihon University School of Dentistry at Matsudo, 2-870-1 SakaechoNishi, Matsudo, Chiba 271-8587, Japan.Tel: +81-47-360-9414 Fax: +8147-364-6295, E-mail address: yamaguchi.masaru@ nihon-u.ac.jp found in periodontal tissues, TNF- $\alpha$ has been shown to trigger apoptosis in osteoblasts and PDL cells ${ }^{11}$.

Apoptosis is a programmed cell death, which includes many components that are necessary for its execution. Two main pathways are known: the extrinsic and intrinsic pathway. The extrinsic pathway involves the participation of Fas-FasL, FADD and caspase 8 whereas the intrinsic pathway involves the participation of Bcl-2 proteins, cytocrome $\mathrm{c}$ and caspase 9 . The activated pathway will depend on the initial stimulus. Reactive oxygen species (ROS) stimulus are considered inducers of both pathways ${ }^{12}$. The extrinsic pathway is triggered by the ROS-induced JNK, which promotes Fas self-activation of the extrinsic pathway to promote cleavage of caspase 8 and subsequent events ${ }^{13}$.

Recent studies have suggested that osteocytes in the alveolar bone adjacent to the hyalinized PDL undergo cell death via apoptosis during rat experimental tooth movement ${ }^{14)}$. The maximum apoptosis occurs 3 days after the application of orthodontic force ${ }^{15}$ ) and if compounds affect the cyclin and/or CDKs, then it may lead to cell cycle arrest. If a cell continues to cycle with its damaged DNA intact, then the apoptotic mechanism is triggered and the cell will undergo apoptosis ${ }^{16)}$.

However, little is known about its effect on apoptosis and the underlying mechanisms reactive in PDL cells. This study focuses on the application of compression force associated with ROS- 
induced apoptosis in PDL cells. The maxillary first molar after the application of the orthodontic force were investigated by immunohistochemical analysis. Compression force treated the cell cycle analysis and apoptosis by flow cytometry. Furthermore, we assayed the effect on ROS generation by DCFDA fluorescence.

\section{Materials and Methods}

\section{In vivo study}

\section{Animals}

The animal experimental protocol in this study was approved by the Ethics Committee for Animal Experiments at the Nihon University School of Dentistry at Matsudo (approval No. AP11MD010). A total of fifteen male 6-week-old Wistar rats of body weight $180 \pm 10 \mathrm{~g}$ (Sankyo Labo Service, Inc., Tokyo, Japan;) were used for the experiments. The animals were maintained in the animal center of Nihon University School of Dentistry at Matsudo in separate cages in a 12-h light/dark environment at a constant temperature of $23^{\circ} \mathrm{C}$, and were provided with food and water ad libitum. The health status of each rat was evaluated by the monitoring of daily body weight for 1 week before the start of the experiments.

\section{Application of orthodontic devices and tissue harvesting}

The animals were anaesthetized with pentobarbital sodium ( $40 \mathrm{mg} / \mathrm{kg}$ body weight) for the application of orthodontic devices. Experimental tooth movement was induced using the method of Asano et al. ${ }^{17}$ ), with a closed-coil spring (wire size: 0.005 inch, diameter: 1/12 inch, Accurate, Inc., Tokyo, Japan) ligated to the maxillary first molar by a 0.008 -inch stainless steel ligature wire (Tomy International, Inc., Tokyo, Japan). The other side of the coil spring was also ligated with the holes in the maxillary incisors drilled laterally just above the gingival papilla with a number $1 / 4$ round bur, using the same ligature wire. The upper first molar was mesially moved by the closed coil spring with a force of $10 \mathrm{~g}$. The duration of the experiment was day 5 .

\section{Tissue preparation}

The experimental periods were set at 1, 3 and 5 days after tooth movement was initiated. The animals were deeply anesthetized by pentobarbital sodium and transcardially perfused with $4 \%$ paraformaldehyde in $0.1 \mathrm{M}$ phosphate buffer, and hereafter the maxilla was immediately dissected and immersed in the same fixative for $18 \mathrm{~h}$ at $4^{\circ} \mathrm{C}$. The specimens were decalcified in $10 \%$ disodium ethylenediamine tetraacetic acid (EDTA, pH 7.4) solution for 4 weeks, and decalcified specimens were dehydrated through a graded ethanol series and embedded in paraffin by the usual methods for preparation. Each sample was sliced into 4- $\mu \mathrm{m}$ sections continuously in the horizontal direction, and were prepared for hematoxylin and eosin staining (H-E), for the terminal deoxynucleotidyl transferase-mediated dUTP nick end labeling
(TUNEL) assay and also for immunohistochemical staining. The periodontal tissues in the mesial part of the distal buccal root of a first upper molar were observed.

\section{TUNEL assay}

Apoptosis was detected by the TUNEL assay using the TACS 2TdT-DAB In Situ Apoptosis Detection Kit (Trevigen, Gaithersburg, MD, USA). The paraffin sections $(4 \mu 1)$ were incubated with proteinase $\mathrm{K}$ (Trevigen), diluted 1: 200 at $37{ }^{\circ} \mathrm{C}$ for $15 \mathrm{~min}$, washed with deionized water, incubated with $3 \%$ $\mathrm{H}_{2} \mathrm{O}_{2}$ for $5 \mathrm{~min}$, and then washed with deionized water again. For the positive control, sections were incubated with DNase I at $37^{\circ} \mathrm{C}$ for $30 \mathrm{~min}$. All sections were incubated with terminal deoxynucleotide transferase (TdT) and Biotin-dUTP at $37^{\circ} \mathrm{C}$ for $1 \mathrm{~h}$ (the negative control sections were not incubated with the TdT enzyme). After washing, the sections were incubated in StrepHRP solution at $37^{\circ} \mathrm{C}$ for $10 \mathrm{~min}$. After washing, the diaminobenzidine (DAB) was added to demarcate the apoptotic cells. The sections were counterstained with $1 \%$ methyl green, and were finally dehydrated and mounted.

\section{Immunohistochemistry}

The immunohistochemical staining was performed as described in this section. The sections were deparaffinized and the endogenous peroxidase activities were quenched by incubation in $3 \% \mathrm{H}_{2} \mathrm{O}_{2}$ in methanol for $30 \mathrm{~min}$ at room temperature (RT). After washing in Tris-buffered saline (TBS), the sections were incubated with polyclonal anti-rabbit caspase 8 (Novus, working dilution, 1:1000), antibodies for $18 \mathrm{~h}$ at $4^{\circ} \mathrm{C}$. Caspase 8 was stained using the Histofine Simple Stain MAX-PO (multi) (Nichirei Biosciences, Tokyo, Japan) according to the manufacturer's protocol. The sections were rinsed with TBS and the final color reactions were performed using $\mathrm{DAB}$. Thereafter, the sections were counter-stained with hematoxylin.

\section{In vitro study}

\section{Human periodontal ligament (hPDL) cell culture}

The hPDL cells were prepared according to a modification of the method of Somerman et al. ${ }^{18)}$ Periodontal ligament tissues were taken from the roots of premolars that were extracted from donors between 15 to 18 years of age for orthodontic reasons with informed consent, and these specimens were used according to a protocol reviewed by the Ethics Committee of Nihon University School of Dentistry at Matsudo (EC 10-019). The periodontal ligament tissues were placed in $35-\mathrm{mm}$ tissue culture dishes and were covered with a sterilized glass coverslip. The cells were maintained in $\alpha$-MEM medium (Gibco, Grand Island, NY, USA), which was supplemented with $100, \mu \mathrm{g} / \mathrm{ml}$ of penicillin-G (Sigma Chemical Co., St.Louis, MO, USA), $50 \mu \mathrm{g} / \mathrm{ml}$ of gentamicin sulphate (Sigma Chemical Co.), $0.3 \mu \mathrm{g} / \mathrm{ml}$ of amphotericin B 
Mari Funakoshi et al.: Compression Force and Periodontal Ligament Cell

(Flow Laboratories, McLean, VA, USA), and 10\% fetal calf serum (Cell Culture Laboratories, Cleveland, OH, USA). The cultures were kept at $37^{\circ} \mathrm{C}$ in a humidified incubator in the presence of $95 \%$ air and $5 \% \mathrm{CO}_{2}$. When the growing cells from each explant reached confluence, they were detached with $0.05 \%$ trypsin (Gibco) in phosphate-buffered saline for $2 \mathrm{~min}$ and were subcultured in culture flasks. Any cells which adhered to the bottom of the flask were discarded to avoid contamination by epithelial cells.

\section{Application of compression force}

In order to reproduce the conditions of pressure during orthodontic tooth movement, we performed the following in vitro experiments as described by Asano et al. ${ }^{17}$. hPDL cells were continuously compressed using a uniform compression method which serves as a model of the pressure at the site of orthodontic movement. The static compression force is thought to mimic that found in vivo during orthodontic treatments. In the present experiments, the cells were stimulated once. A cell disk 35- mm in diameter was placed over subconfluent cell layers in the dishes, on top of which a slide glass was placed. The compression force was then controlled by placing lead granules in the slide glass. Before the application of the compression force, the cells were pre-incubated for $18 \mathrm{~h}$ in culture medium containing $1 \%$ fetal calf serum, and thereafter were subjected to $1.0 \mathrm{~g} / \mathrm{cm}^{2}$ of CF for $24 \mathrm{~h}$.

\section{ROS detection}

In order to detect the ROS in the cells, an ROS detection kit was used Image-iT ${ }^{\mathrm{TM}}$ LIVE Green Reactive Oxygen Species Detection Kit (Molecular Probes, Inc, Eugene, OR, USA). The kit was used as described in the manufacturer's protocol. Intracellular, unspecific ROS were marked with carboxy$\mathrm{H}_{2}$ DCFDA solution and the cell nuclei with Hoechst 33342 solution. After washing with HBSS (Gibco), the cells were fixed. Tert-butyl hydroperoxide (TBHP, at a concentration of $100 \mu \mathrm{M}$ ) which served as a positive control was incubated for the same duration as the samples.

\section{Wound healing assay}

hPDL cells were cultured on 35-mm dishes until they reached confluence. A linear wound track was made by a P-1000 pipette tip to scratch on the confluent cell monolayer. The wounds were marked and scored in each dish and the plates were then washed twice with culture medium. The cells migrating into the wound were photographed $24 \mathrm{~h}$ after the incubation following wounding.

\section{Flow cytometry for the cellular propidium iodide (PI) assay and} cell cycle analysis

After the compression force was applied, the cells were washed with PBS, and detached with $0.05 \%$ trypsin. After washing and fixing with $70 \%$ ice-cold alcohol overnight at $20^{\circ} \mathrm{C}$, the cells were collected and resuspended in PBS containing $40 \mu \mathrm{g} / \mathrm{ml} \mathrm{PI,} 100$ $\mu \mathrm{g} / \mathrm{ml}$ RNase. They were then incubated at $37^{\circ} \mathrm{C}$ for $30 \mathrm{~min}$ and were subsequently analyzed by flow cytometry.

\section{Analysis of apoptosis by flow cytometry}

A FITC-Annexin V Apoptosis Detection Kit I (BD Biosciences Pharmingen, San Jose, CA, USA) was used according to the supplier's protocol. After the compression force was applied, the cells were gently trypsinized and collected by centrifugation. Approximately $5 \times 10^{6}$ cells were washed twice with cold PBS and resuspended in $500 \mu 1$ of $1 \times$ binding buffer. Five microlitres of annexin $\mathrm{V}$ and $5 \mu \mathrm{l}$ of PI were then added to the cell suspensions and the samples were incubated in the dark at room temperature for $15 \mathrm{~min}$. The fluorescence observed following annexin V-FITC (which binds to apoptotic cells) binding and PI (which stains necrotic cells) staining was measured quantitatively using a flow cytometer (Becton Dickinson Immunocytometry Systems, SanJose, CA, USA).

\section{Detection of apoptosis by Hoechst 33258 staining}

The nuclear fragmentation was visualized by staining the apoptotic nuclei with Hoechst 33258. The cells were fixed with $4 \%$ paraformaldehyde for $30 \mathrm{~min}$ at $\mathrm{RT}$ and then washed once with $1 \times \mathrm{PBS} / 0.1 \%$ triton-X for $5 \mathrm{~min}$ at RT. Hoechst $33258(2.5$ $\mu \mathrm{g} / \mathrm{ml}$ ) was added to the fixed cells, followed by incubation for 30 min at RT; the cells were then washed with $1 \times \mathrm{PBS} / 0.1 \%$ triton$\mathrm{X}$. The cells were mounted and examined by fluorescence microscopy. The apoptotic cells were identified by the condensation and fragmentation of their nuclei. The percentage of apoptotic cells was calculated from the ratio of apoptotic cells to the total cells counted.

\section{Statistical methods}

The values in each figure represent the mean \pm standard deviation (S.D.) for each group. Values are shown as the means \pm S.D. A Mann-Whitney's U-test was used to compare the means of the groups. The values of $p<0.05$ considered to indicate a significant difference.

\section{Results}

\section{In vivo study}

\section{Histological changes in the periodontal tissues during tooth} movement

In the control group, PDL specimens were composed of relatively dense connective tissue fibres and fibroblasts that regularly ran in a horizontal direction from the root cement towards the alveolar bone. In the compression force group, the arrangement of the fibres and fibroblasts became coarse and irregular, and blood capillaries were compressed on day 3 (Fig. 1). 


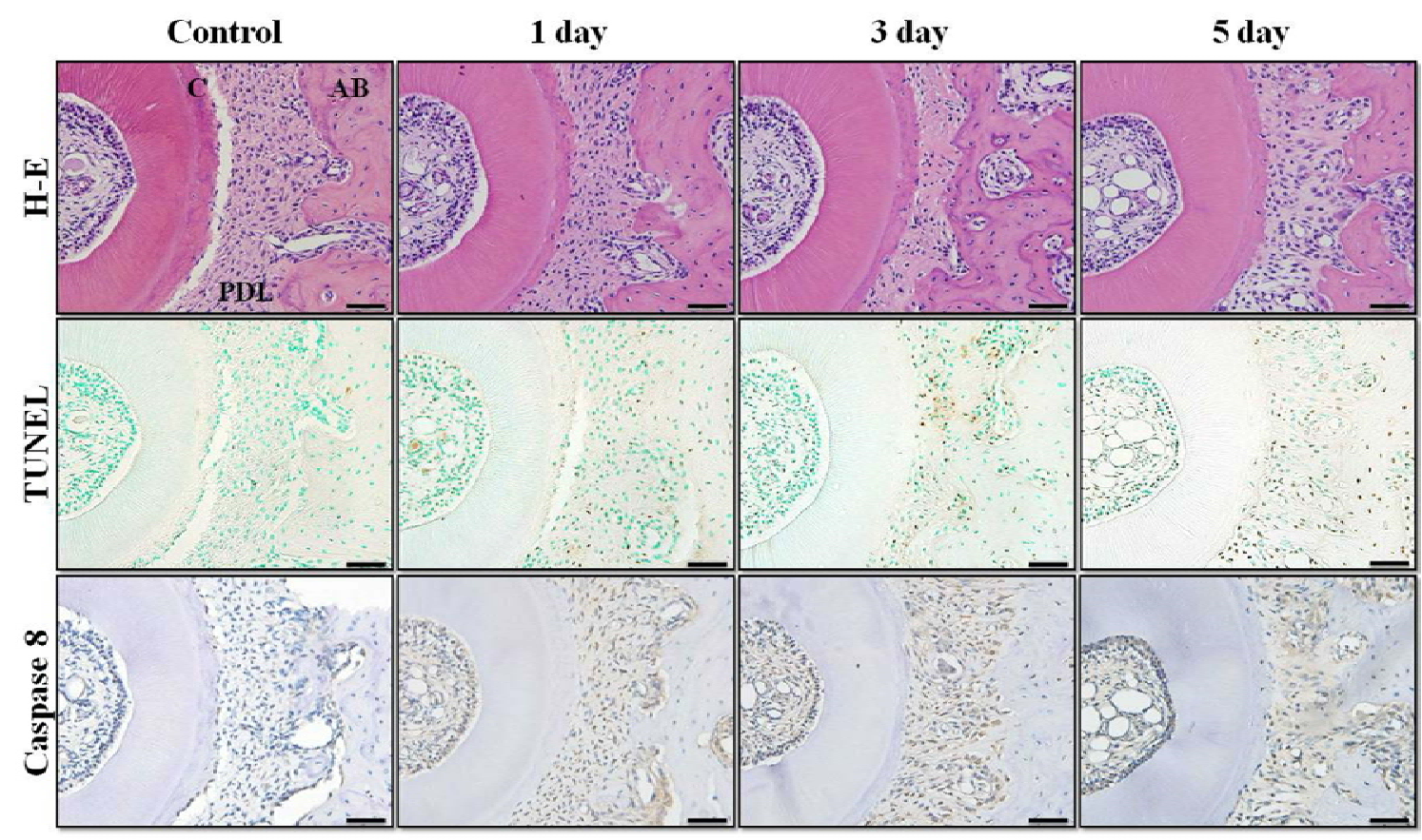

Figure 1. Light macroscopic images of the effects of TUNEL staining and the immunohistochemical staining for caspase 8 . The control specimen shows that there are few TUNEL and caspase 8-positive cells in PDL. The increased levels of TUNEL and caspase 8 were shown after the application of the orthodontic force. C: cementum, PDL: periodontal ligament, AB: alveolar bone. Bar $=50 \mu \mathrm{m}$

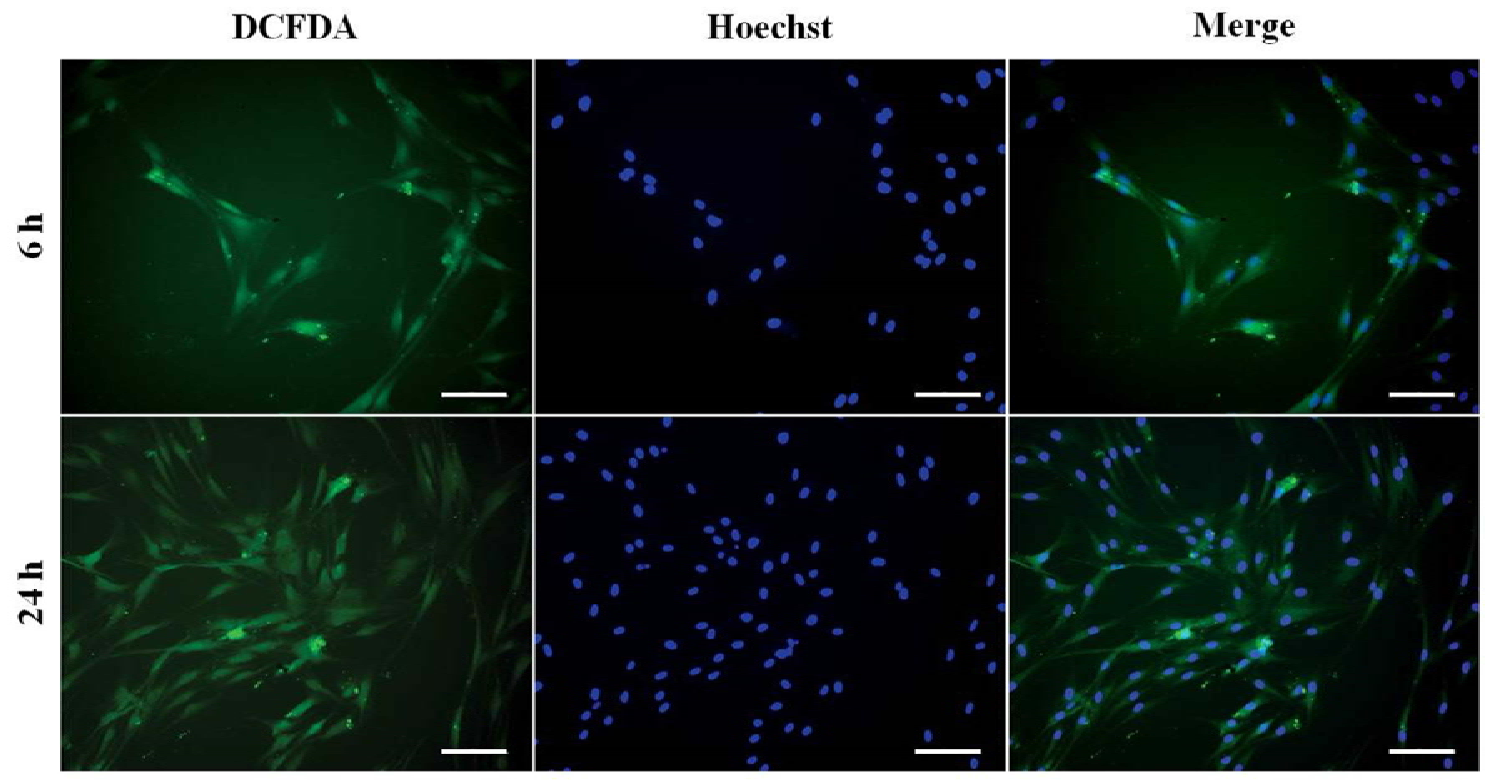

Figure 2. The compression force increases the intracellular ROS production in hPDL cells. The compression force was applied to the $\mathrm{hPDL}$ cells for 6 and $24 \mathrm{~h}$ in the presence of DCFDA and measured by fluorescence microscopy. Bar $=100 \mu \mathrm{m}$

\section{Induction of apoptosis of PDL cells with orthodontic force in} rat

To confirm the apoptotic effect of periodontal ligament cells after the application of the orthodontic force, TUNEL stain and caspase 8 immunohistochemistry were used. The PDL cells after the application of the orthodontic force increased TUNEL and caspase 8 -positive cells at day 1 , reached to a maximum peak at day 5. Only a few TUNEL and caspase 8-positive cells were present in the control (Fig. 1). These results showed that cells subjected to a continuous compression force had strong staining in comparison to that of the control cells.

\section{Compression force induced ROS production}

Production of ROS was monitored using DCFH-DA. As shown 
(a)

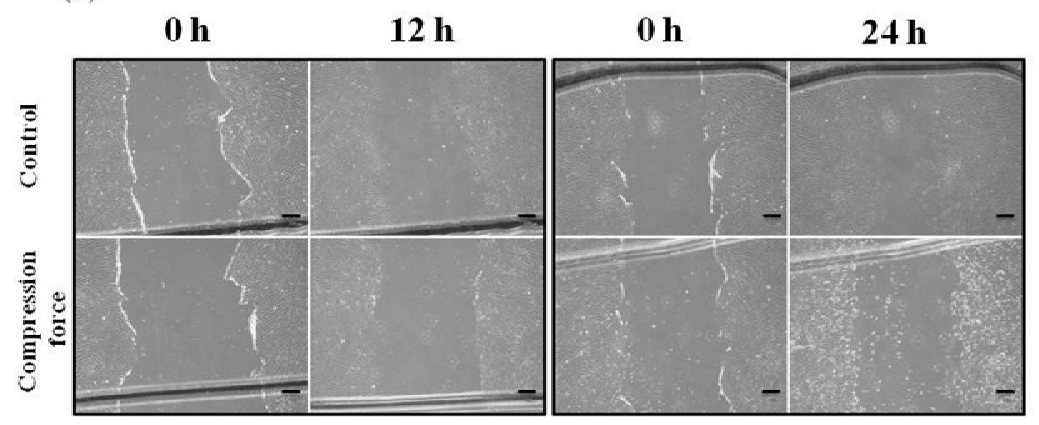

(b)

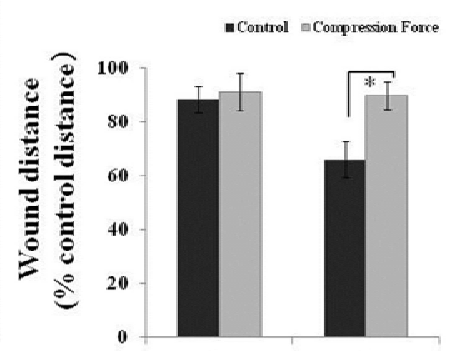

Figure. 3 Effect of the compression force on the repopulation hPDL cells. A monolayer of hPDL cells was scratched with a P-1000 pipette tip, producing a single straight-wound line and the application of the compression force on the cultures for various time points. Following the application, the cultures were maintained in the appropriate conditions for various periods of time prior to making the observations and taking the photographs Original magnification $40 \times(a)$. The wound healing, rated in percentage, was determined as the mean \pm standard deviation (b).

(a)

$0 \mathbf{h}$

$6 \mathrm{~h}$

24 h
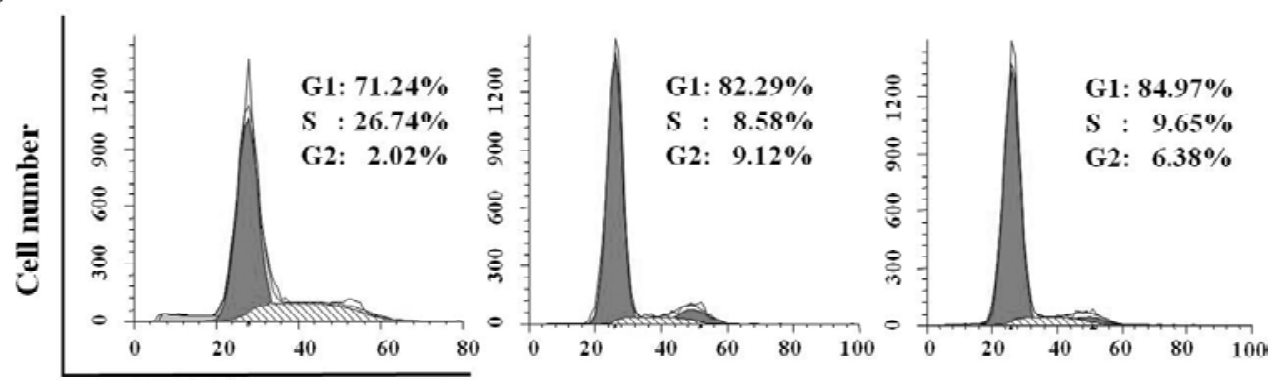

DNA Content

(b)
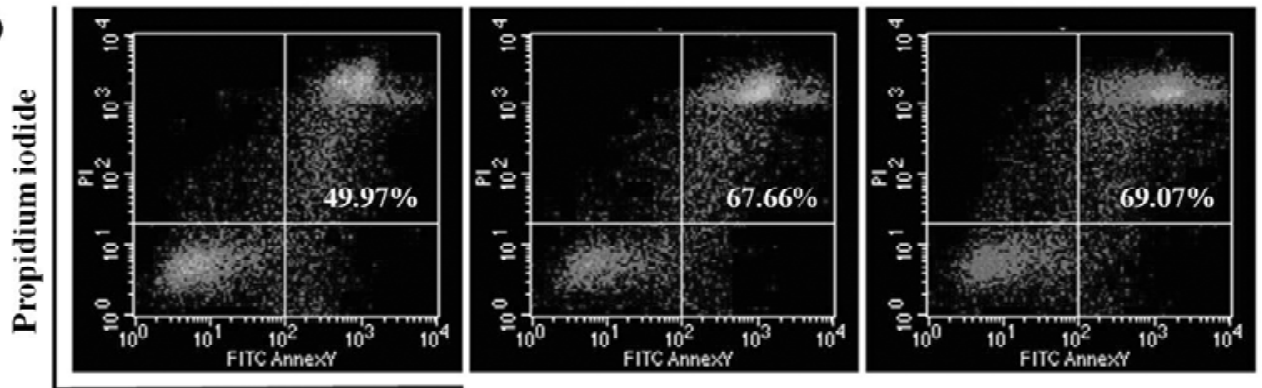

FITC Annexin V

Figure. 4 Compression force induced G1 phase arrest in hPDL cells. The histogram plotting and quantification of each cell cycle phase, showing a decrease in the population of cells in the $\mathrm{S}$ and an increase in the population of cells in the G1 phases for 6 and $24 \mathrm{~h}$ (a). Flow cytometric analysis by annexin-V-FITC/PI dual staining. The cells were labeled with FITC conjugate and were quantified following analysis in a FACS. The upper right quadrant indicates the late stages of apoptosis (VFITC+/PI+) was increased from $49.97 \%$ to $69.07 \%$ at $24 \mathrm{~h}(\mathrm{~b})$.

in Figure 2, the intracellular ROS levels were increased after compression force treatment for $6 \mathrm{~h}$, and the levels of ROS production was further increased at $24 \mathrm{~h}$. Results showed that a time-dependent increase in ROS production was observed in the PDL cells after the application of compression force.

\section{Wound healing assay}

PDL cells were used to study cell motility and migration using an in vitro wound healing assay. Figure 3 showed the treatment area of wound after the application of the compression force.
Compression force group showed the delayed closure than the control group. At $24 \mathrm{~h}$ the compression force group had significantly less motility and migration movement than the control groups.

\section{Analysis of compression force-induced cell cycle arrest and apoptosis}

To assess the application of compression force for various periods of time on cell cycle progression, we have performed flow cytometry analyses in PDL cells. The results show that compres- 


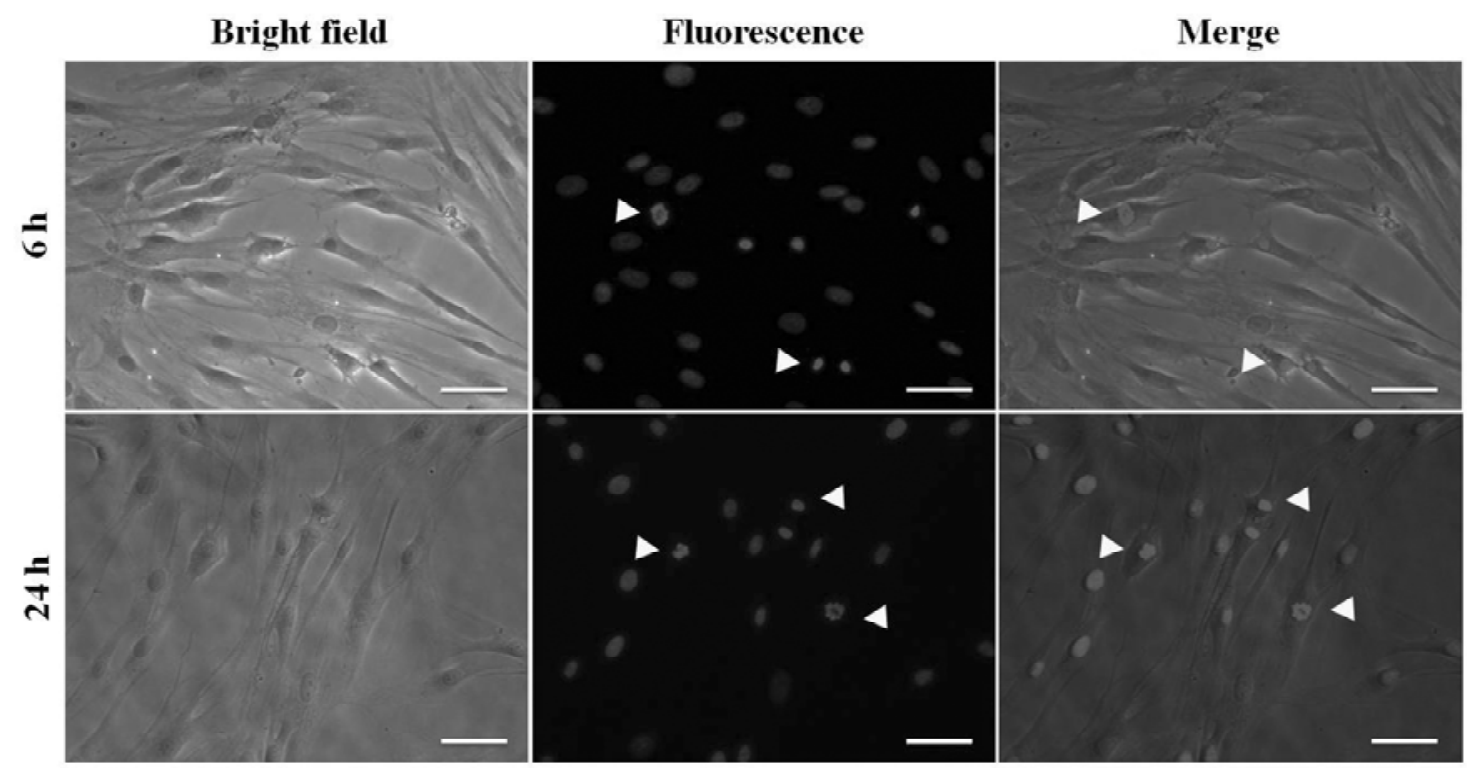

Figure. 5 The nucleus condensation was observed with Hoechst 33258 after the compression force was applied to the cells for 6 and $24 \mathrm{~h}$. The arrows indicate apoptotic cells. Bar $=50 \mu \mathrm{m}$.

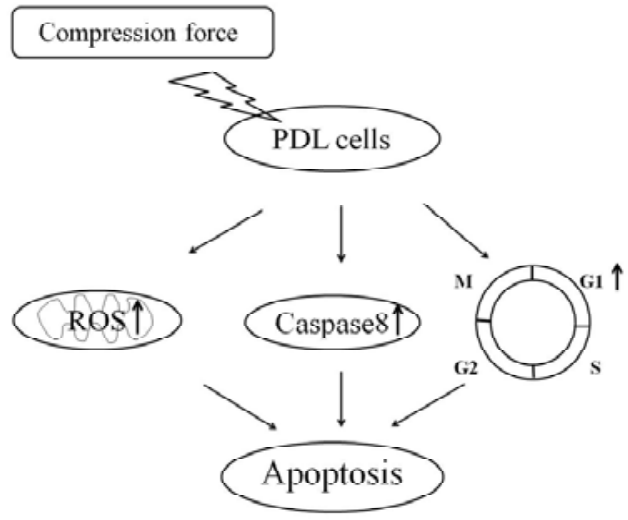

Figure. 6 Schematic model for compression force induced apoptosis in hPDL cells. Application of the compression forceinduced G1 arrest, caspase 8 protein and ROS in hPDL cells and they induced apoptosis.

sion force contributed to gradual increase and decrease in percentage of cells in G1 phase and S phase, respectively compares to the control (Fig. 4a). By staining the cells with annexin VFITC and PI, FACS was used to determine the compression forceinduced apoptotic cells. The upper right quadrant indicates the late stages of apoptosis (VFITC+/PI+) was increased from $49.97 \%$ to $69.07 \%$ at $24 \mathrm{~h}$ (Fig. 4b). The experiment indicated a timedependent induction of apoptosis of hPDL cells in response to the compression force for $24 \mathrm{~h}$. Hoechst 33258 staining was used to determine the effects of apoptosis induced by application of compression force. As shown in Figure 5, Hoechst 33258 staining showed the presence of nuclear condensation at $6 \mathrm{~h}$ after the application of the compression force, and a gradual increase in the number of condensed or fragmented nuclei (apoptosis) was observed for $24 \mathrm{~h}$.

\section{Discussion}

This study demonstrated the induction of apoptosis and the subsequent decrease in cellular viability of the PDL cells following the application of compression force.

In this study, it was observed that TUNEL and caspase 8positive cells are highest at day 5 in vivo (Fig. 1). During tooth movement in vivo, recent studies have reported that the number of TUNEL-positive periodontal ligament cells increases at $12 \mathrm{~h}$ and reaches a maximum at $24 \mathrm{~h}^{19)}$. In addition, in vivo, the ratio of TUNEL-positive cells on the pressure side of the periodontal ligament increased up to day $28^{20)}$. The effect of the compression force on PDL cells may occur through an apoptotic mechanism. Hatai et al. ${ }^{19)}$ reported that they applied mechanical stress during orthodontic tooth movement by using the $50 \mathrm{~g}$ nickel titanium and Mabuchi et al. ${ }^{20)}$ reported using the Waldo method. It is believed that it varies in a tooth migration method and a movement power that a day of the expression is different from them.

Apoptosis consists of two main pathways: intrinsic (mitochondrial) and extrinsic (receptors-related). Caspases are common to both pathways. Caspases are cysteine proteases that cleave a set of proteins in order to initiate and promote apoptotic signaling. Caspase 8 participates in the extrinsic pathway and is activated by Fas-FasL signal transduction. Caspase 9 is the mediator of the intrinsic pathway, and an alteration in oxidative phosphorylation, hypoxia and oxidative stress can induce the activation of caspase $9^{12}$. We previously studied the mRNA expression of TNF- $\alpha$ and found that it increased significantly 
Mari Funakoshi et al.: Compression Force and Periodontal Ligament Cell

after the application of compression force ${ }^{21)}$. We therefore hypothesize that the mechanism of apoptosis through caspase 8 activation is mediated by TNF- $\alpha$.

We previously reported the increased expressions of cytokines and chemokines during experimental tooth movement because of the application of heavy force $(50 \mathrm{~g})$ in vivo and the effects of compression forces $\left(0-4.0 \mathrm{~g} / \mathrm{cm}^{2}\right)$ in vitro ${ }^{17,21)}$. The highest amount of cell damage was $16.9 \%$ in the compression force ( $4.0 \mathrm{~g}$ ) group ${ }^{21)}$. It is difficult to determine the optimal force during therapeutic orthodontic tooth movement, because periodontal tissue reactions vary among individuals. Based on the aforementioned facts, we hypothesized that an optimal compression force $\left(1.0 \mathrm{~g} / \mathrm{cm}^{2}\right)$ applied to periodontal ligament cells can induce in vitro apoptosis via ROS generation and cell cycle arrest and that may accelerate their downstream signals. As expected, the apoptotic periodontal ligament cells were increased by the application of $1.0 \mathrm{~g} / \mathrm{cm}^{2}$ compressive force. We demonstrated that the compression force increases ROS production in hPDL cells (Fig. 2). Compression force-induced G1 arrest and apoptosis in human periodontal ligament cells was at least partly mediated by ROS generation.

When we assayed ROS generation in the human PDL cells, we found that compression force induced a large increase in the fluorescence of the $\mathrm{H}_{2} \mathrm{O}_{2}$ indicator DCF, indicating that compression force stimulated the intracellular generation of peroxides in PDL cells. Previous studies have shown that the mechanical compression of the spinal nerve increases the recruitment of inflammatory cells to these tissues, resulting in ROS production $^{22}$. The elevation of ROS may deplete cellular glutathione, damage DNA, activate check-point kinases and regulate the cell cycle and apoptosis-related genes ${ }^{23,24)}$. In promoting PDL cells apoptosis, the compression force may hamper wound healing. In this study, the proliferation decreased in hPDL cells $24 \mathrm{~h}$ after the application of the compression force (Fig. 3). Cell cycle progression is achieved through a tightly controlled cascade of cellular events. In the present study, we found that the compression force suppressed the PDL cell proliferation by arresting the cell cycle in the G1 phase (Fig. 4a). The highest accumulation of cells at the G1 phase was observed after $24 \mathrm{~h}$ of incubation with compression force, suggesting that ROS generation preceded cell-cycle arrest by compression force. The G1 arrest is always used as the marker for cellular differentiation ${ }^{25}$, 26), and an apparent G1 arrest has been observed during the differentiation in previous research ${ }^{27,28}$. Recent research has shown that cyclic tensile stress on PDL cells arrested cells in the G1 phase, and there were gene changes related to apoptosis and the cell cycle. Cell cycle-associated genes developed by the stretch force were directly related to the change of the cell cycle ${ }^{29)}$. It controls G2/M checkpoint and contributes to the switch-like, allor-nothing behavior of the cell in deciding to commit to mitosis ${ }^{30)}$. Like all cyclins, levels of cyclin B1 oscillate over the course of the cell cycle. Just prior to mitosis, a large quantity of cyclin B1 is present in the cell, but it is inactive due to the phosphorylation of $\mathrm{Cdk} 1^{31)}$. This suggests that the cell cycle arrest under the compression force may result in the expression of cell cycleassociated genes.

To verify that these events occur, a flow cytometric analysis was performed. The flow cytometric analysis of apoptosis is indicative of the extent of apoptosis induced by the compression force. The fraction of apoptotic hPDL cells was significantly upregulated, in comparison to the control, following exposure to 6 or 24 h. Figure. $4 \mathrm{~b}$ showed that the rate of apoptosis reached a peak when the cells were compressed for $24 \mathrm{~h}$. These results are supported by those previously reported in other models namely the stretching force model in hPDL cells ${ }^{32}$ and the compression force model in osteoblast ${ }^{33)}$. Furthermore, after staining with Hoechst 33258, the PDL cells which were subjected to a compression force exhibited the typical morphological features of apoptosis (Fig. 5). As the time and dose increased, the number of apoptotic cells increased, as indicated by the presence of fragmented nuclei and apoptotic bodies. The compression force therefore exerted a significant effect on the hPDL cells by increasing the number of apoptotic cells (Fig. 6). These suggest that both caspase 8 and caspase 9 signaling pathways may have contributed to the compression force-induced apoptosis in hPDL cells.

In conclusion, we herein elucidated the mechanisms by which compression force affects hPDL cells. Our findings suggest that the application of compression force to hPDL cells produces ROS which initiates the activation of the apoptosis pathway, thus leading to cell cycle arrest in the G1 phase.

\section{Acknowledgments}

This study was supported by a Grant-in-Aid for Scientific Research from the Japan Society for the Promotion of Science (C22592297, C23792449, C23593044).

\section{References}

1. Pavlin D, Dove SB, Zadro R and Gluhak-Heinrich J. Mechanical loading stimulates differentiation of periodontal osteoblasts in a mouse osteoinduction model: Effect on type I collagen and alkaline phosphatase genes. Calcif Tissue Int 67: 163-172, 2000

2. Beertsen W, McCulloch CAG and Sodek J. The periodontal ligament: A unique, multifunctional connective tissue. Periodontol 2000 13: 20-40, 1997

3. Krishnan V and Davidovitch Z. Cellular, molecular, and tissue-level reactions to orthodontic force. Am J Orthod Dentofacial Orthop 129 469: 1-32, 2006

4. Reitan K and Rygh P. Orthodontics: current principles and techniques 2nd ed. Mosby Year Book Inc. St Louis, 
1994,pp.96-192

5. Jager A, Zhang D, Kawarizadeh A, Tolba R, Braumann B, Lossdorfer S and Gotz W. Soluble cytokine receptor treatment in experimental orthodontic tooth movement in the rat. Eur J Orthod 27: 1-11, 2005

6. Tzannetou S, Efstratiadis S, Nicolay O, Grbic J and Lamster I. Comparison of levels of inflammatory mediators IL-1beta and betaG in gingival crevicular fluid from molars, premolars, and incisors during rapid palatal expansion. Am J Orthod Dentofacial Orthop 133: 699-707, 2008

7. Seifi M, Eslami B and Saffar AS. The effect of prostaglandin E2 and calcium gluconate on orthodontic tooth movement and root resorption in rats. Eur J Orthod 25: 199-204, 2003

8. Jerome J, Brunson T, Takeoka G, Foster C, Moon HB, Grageda $\mathrm{E}$ and Zeichner-David M. Celebrex offers a small protection from root resorption associated with orthodontic movement. J Calif Dent Assoc 33: 951-959, 2005

9. Najat A, Lars F, Pongsri B and Moiz B. Orthodontic movement induces high numbers of cells expressing IFN-gamma at mRNA and protein levels. J Interferon Cytokine Res 20: 712,2000

10. Baud, V and Karin, M. Signal transduction by tumor necrosis factor and its relatives. Trends Cell. Biol 11: 372-377, 2001

11. Thammasitboon K, Goldring SR and Boch JA. Role of macrophages in LPS-induced osteoblast and PDL cell apoptosis. Bone 38: 845-852, 2006

12. Kalia $S$ and Bansal MP. Regulation of apoptosis by caspases under oxidative stress conditions in mice testicular cells: in vitro molecular mechanism. Mol Cell Biochem 322: 43-52, 2009

13. Maheshwari A, Misro MM, Aggarwal A, Sharma RK and Nandan D. Pathways involved in testicular germ cell apoptosis induced by $\mathrm{H}_{2} \mathrm{O}_{2}$ in vitro. FEBS J 276: 870-881, 2009

14. Hamaya M, Mizoguchi I, Sakakura Y, Yajima T and Abiko Y. Cell death of osteocytes occurs in rat alveolar bone during experimental tooth movement. Calcif Tissue Int 70: 117-126, 2002

15. Rana MW, Pothisiri V, Killiany DM and Xu XM. Detection of apoptosis during orthodontic tooth movement in rats. Am J Orthod Dentofacial Orthop 119: 516-521, 2001

16. Wu CC, Lin JP, Yang JS, Chou ST, Chen SC, Lin YT, Lin HL and Chung JG. Capsaicin induced cell cycle arrest and apoptosis in human esophagus epidermoid carcinoma CE 81T/VGH cells through the elevation of intracellular reactive oxygen species and $\mathrm{Ca}^{2+}$ productions and caspase- 3 activation. Mutat Res 601: 71-82, 2006

17. Asano M, Yamaguchi M, Nakajima R, Fujita S, Utsunomiya T, Yamamoto H and Kasai K. IL- 8 and MCP-1 induced by excessive orthodontic force mediates odontoclastogenesis in periodontal tissues. Oral Dis 17: 489-498, 2011

18. Somerman MJ, Archer SY, Imm GR and Foster RA . A comparative study of human periodontal ligament cells and gingival fibroblasts in vitro. J Dent Res 67: 66-70, 1988

19. Hatai T, Yokozeki M, Funato N, Baba Y, Moriyama K and Ichijo $\mathrm{H}$. Apoptosis of periodontal ligament cells induced by mechanical stress during tooth movement. Oral Dis 7 : 287-290, 2001

20. Mabuchi R, Matsuzaka K and Shimono M. Cell proliferation and cell death in periodontal ligaments during orthodontic toothmovement. J Periodontal Res 37: 118-124, 2001

21. Mitsuhashi M, Yamaguchi M, Kojima T, Nakajima R and Kasai K. Effects of HSP70 on the compression force-induced TNF- $\alpha$ and RANKL expression in human periodontal ligament cells. Inflamm Res 60: 187-194, 2011

22. Xu W, Chi L, Xu R, Ke Y, Luo C, Cai J, Qiu M, Gozal D and Liu R. Increased production of reactive oxygen species contributes to motor neuron death in a compression mouse model of spinal cord injury. Spinal Cord 43: 204-213, 2005

23. Sarsour EH, Kumar MG, Chaudhuri L, Kalen AL and Goswami PC. Redox control of the cell cycle in health and disease. Antioxid Redox Signal 11: 2985-3011, 2009

24. Ansteinsson V, Solhaug A, Samuelsen JT, Holme JA and Dahl JE. DNA-damage, cell cycle arrest and apoptosis induced in BEAS-2B cells by 2-hydroxyethyl methacrylate (HEMA). Mutat Res 723: 158-164, 2011

25. Ding QM, Ko TC and Evers BM. Caco-2 intestinal cell differentiation is associated with G1 arrest and suppression of CDK2 and CDK4. Am J Physiol Cell Physiol 275: 11931200, 1998

26. Thompson T, Danilenko M, Vassilev L and Studzinski GP. Tumor suppressor p53 status does not determine the differentiation-associated G1 cell cycle arrest induced in leukemia cells by 1, 25-dihydroxyvitamin $\mathrm{D}_{3}$ and antioxidants. Cancer Biol Ther 10: 344-350, 2010

27. Lassar AB, Skapek SX and Novitch B. Regulatory mechanisms that coordinate skeletal muscle differentiation and cell cycle withdrawal. Curr Opin Cell Biol 6: 788-794, 1994

28. Ruch JV, Leot $\mathrm{H}$ and Bègue-Kirn C. Odontoblast differentiation. Int J Dev Biol 39: 51-68, 1995

29. Wang Y, Li Y, Fan X, Zhang Y, Wu J and Zhao Z. Early proliferation alteration and differential gene expression in expression in human periodontal ligament cells subjected to cyclic tensile stress. Arch Oral Biol 56: 177-186, 2011

30. Sartor H, Ehlert F, Grzeschik KH, Müller R and Adolph S. Assignment of two human cell cycle genes, CDC25C and CCNB1, to 5q31 and 5q12, respectively. Genomics 13: 911-912, 1992 
Mari Funakoshi et al.: Compression Force and Periodontal Ligament Cell

31. Shanahan, F, Seghezzi, W, Parry, D, Mahony, D, and Lees, E. Cyclin E associates with BAF155 and BRG1, components of the mammalian SWI-SNF complex, and alters the ability of BRG1 to induce growth arrest. Mol Cell Biol 19: 1460-1469, 1999

32. Zhong W, Xu C, Zhang F, Jiang X, Zhang X and Ye D.
Cyclic stretching force-induced early apoptosis in human periodontal ligament cells. Oral Dis 14: 270276, 2008

33. Goga Y, Chiba M, Shimizu Y and Mitani H.Compressive force induces osteoblast apoptosis via caspase-8. J Dent Res 85: 240-242, 2006 
J.Hard Tissue Biology Vol. 22(1):41-50, 2013 